\title{
Los resultados de la Iniciativa de la Ayuda para el Comercio en América Latina: Una primera valoración *
}

\section{FERNANDO RUEDA-JUNQUERA}

Departamento de Economía Aplicada, UNIVERSIDAD DE BURGOS, ESPAÑA. Email: frueda@ubu.es

\author{
MARIOLA GOZALO-DELGADO \\ Departamento de Economía Aplicada, UNIVERSIDAD DE BURGOS, ESPAÑA. E- \\ mail:mgozalo@ubu.es
}

\section{RESUMEN}

En el contexto actual de ajustes presupuestarios por parte de numerosos donantes, existe una creciente presión pública a favor de la rendición de cuentas por el uso de los recursos destinados a la ayuda oficial al desarrollo. De ahí, la necesidad de medir y evaluar los resultados de los proyectos y programas financiados con dicha ayuda. El objetivo de este artículo es ofrecer una primera valoración de los resultados de la Iniciativa de la Ayuda para el Comercio para el caso de América Latina. Para ello, se aplica un doble enfoque metodológico cuantitativo y cualitativo, utilizando el índice de facilitación del comercio y los relatos de experiencias concretas.

Palabras clave: Cooperación al desarrollo, gestión para resultados de desarrollo, ayuda para el comercio, América Latina.

\section{The Results of the Initiative of Aid for Trade in Latin America: A First Assessment}

\begin{abstract}
In the current context of budgetary adjustments on the part of numerous donors, there is an increasing public pressure in favour of the accountability for the use of the resources devoted to official development assistance. That is why it is necessary to measure and evaluate the results of the projects and programmes financed by that assistance. The goal of this article is to offer a first assessment of the results of the Initiative of Aid for Trade for the case of Latin America. To achieve this goal, a double quantitative and qualitative approach is applied, involving the use of the Enabling Trade Index and the case stories of aid for trade projects and programmes.

Keywords: Development Cooperation, Managing for Development Results, Aid for Trade, Latin America.

Clasificación JEL: F35, F10, O54

\footnotetext{
${ }^{*}$ El presente trabajo forma parte del proyecto CeALCI 11/09. Los autores agradecen el apoyo financiero a dicho proyecto por parte del Programa de Investigación de la Fundación Carolina. Asimismo, agradecen los comentarios y sugerencias realizados por dos evaluadores anónimos. La responsabilidad sobre posibles errores $u$ omisiones es exclusiva de los autores.
}

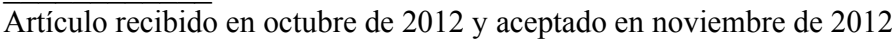

Artículo disponible en versión electrónica en la página www.revista-eea.net, ref. ə-30316 


\section{INTRODUCCIÓN}

La crisis económica y financiera internacional ha alentado comportamientos proteccionistas que pueden limitar la contribución del comercio al crecimiento económico y a la reducción de la pobreza en los países en desarrollo (PED). El que esto acabe ocurriendo no sólo va a depender de los resultados de las negociaciones comerciales multilaterales en el marco de la Ronda de Doha, sino también de las posibilidades reales de los PED para superar las restricciones internas de oferta que les impide aprovecharse de un potencial comercio internacional más liberalizado. Por ello, en 2005 la Organización Mundial del Comercio (OMC) impulsó -en paralelo con la Ronda de Doha- la Iniciativa de la Ayuda para el Comercio (ApC) destinada a proporcionar ayuda oficial al desarrollo (AOD) adicional para superar dichas restricciones internas en los PED (Hoekman y Prowse, 2005; IMF/World Bank, 2005; OECD, 2006, 2009a y 2009b; Page, 2007; OECD/WTO, 2007, 2009 y 2011; Njinkeu y Cameron, 2008; UNDP, 2008; De Lombaerde y Lakshmi, 2009; Hoekman y Wilson, 2010; Cadot et al., 2011; Basnett et al., 2012).

El mantenimiento futuro del apoyo político y público a esta Iniciativa va a venir condicionado por su capacidad de visibilizar resultados significativos en los proyectos y programas de ApC, ya que la Gran Recesión de 2008-2010 ha reducido la disponibilidad de recursos públicos en la comunidad de donantes. La necesidad de obtener resultados es cada vez mayor tanto por esta creciente presión pública de rendir cuentas por el uso de los recursos destinados a la Iniciativa, como por el compromiso adquirido por los países receptores y donantes de orientar la gestión de la ApC hacia el logro de resultados en términos de desarrollo. Aunque todavía no se cuenta con información suficiente como para realizar una evaluación concluyente sobre los resultados de la Iniciativa, es importante que en el contexto actual se acometa una primera valoración de los mismos. Por esta razón, el objetivo de este artículo es llevar a cabo esa primera aproximación valorativa para el caso de América Latina, empleando un doble enfoque metodológico de carácter cuantitativo y cualitativo a partir de la información disponible.

La estructura del resto del artículo es la siguiente. La sección 2 examina el principio de la gestión para resultados de desarrollo, que ha guiado la aplicación de la Iniciativa de la ApC. La sección 3 presenta y justifica la metodología utilizada en el estudio. Con esta base, las tres secciones posteriores se dedican a la aplicación de dicha metodología al caso de América Latina, en concreto: la sección 4 muestra las principales características de los flujos de $\mathrm{ApC}$ en dicha región, la sección 5 valora los resultados de la $\mathrm{ApC}$ en la región a través de un indicador cuantitativo, el Índice de Facilitación del Comercio, y la sección 6 valora los resultados por medio de un indicador cualitativo, el relato de expe- 
riencias concretas en la región. Por último, la sección 7 recoge las principales conclusiones del estudio realizado.

\section{EL PRINCIPIO DE LA GESTIÓN PARA RESULTADOS DE DESARROLLO EN LA AYUDA PARA EL COMERCIO}

La provisión de la ApC -como parte integrante de la AOD- está sujeta a los principios de la Declaración de París sobre la eficacia de la ayuda suscrita en 2005, así como a las directrices posteriores emanadas de los dos Foros de Alto Nivel sobre eficacia celebrados en Accra (2008) y Busán (2011). Aunque los cinco principios de dicha Declaración -apropiación, alineación, armonización, gestión orientada a resultados y mutua responsabilidad- son esenciales para lograr una ayuda eficaz, ha ido creciendo un cierto consenso -como se ha constatado en el último Foro de Busán (OECD, 2011a, p.3)- en considerar la gestión orientada a resultados como un principio prioritario. Este enfoque de la gestión no es una noción nueva, ya que sus primeros fundamentos comenzaron a establecerse en el seno de la empresa privada en los años cincuenta y posteriormente, se trasladaron a la gestión pública en los años setenta. En el ámbito específico de la cooperación al desarrollo, este tipo de gestión ha ido evolucionando desde los modelos lógicos de planificación, seguimiento y evaluación hasta los actuales basados en la Gestión para Resultados de Desarrollo (GpRD).

Las tres Mesas Redondas Internacionales sobre Resultados de Desarrollo celebradas en Washington (2002), Marrakech (2004) y Hanoi (2007) fueron introduciendo la relevancia de la gestión orientada a resultados en términos de desarrollo dentro del debate sobre la eficacia de la ayuda y de este modo, fueron contribuyendo a su actual conceptualización (OCDE y Banco Mundial, 2006, 2007 y 2008; PNUD, 2009; García-López y García-Moreno, 2010; OECD, 2011b; Mudarra, 2012). ${ }^{1}$ En base al convenio de la Mesa Redonda de Marrakech, el Manual de Buenas Prácticas sobre la GpRD del Comité de Ayuda al Desarrollo (CAD) define la GpRD como "una estrategia de gestión centrada en el desempeño del desarrollo y en las mejoras sostenibles en los resultados del país" (OCDE y Banco Mundial 2006, p. 1) Esta estrategia proporciona un marco de gestión coherente en el que los recursos financieros, humanos y materiales asignados a los proyectos de cooperación se dirigen hacia la consecución de resultados esperados de desarrollo, de tal modo que el foco de atención se coloca en los resultados medibles en las diferentes fases del proceso de desarrollo promovido por dichos proyectos.

La GpRD se basa en las teorías de gestión del cambio en el desarrollo, haciendo hincapié en tres ideas fundamentales (OCDE y Banco Mundial, 2007,

\footnotetext{
${ }^{1}$ Para un análisis más completo de las diferentes mesas redondas y de la GpRD, puede consultarse su dirección de Internet: www.mfdr.org.
} 
p.8): primero, la concreción de las metas, esto es, el establecimiento de objetivos y resultados claros que proporcionen una dirección para el cambio deseado en el proceso de desarrollo del país receptor; segundo, la causalidad o "cadena de resultados" que conduce hacia el cambio deseado; y tercero, la mejora continua por medio de la medición regular de los componentes de esa cadena.

La Figura 1 ilustra la cadena de resultados adaptada a la Iniciativa de la ApC. Esta cadena muestra las relaciones de causa-efecto entre los proyectos y programas de $\mathrm{ApC}$ y los objetivos de desarrollo perseguidos con los mismos: los insumos y actividades de los proyectos y programas conducen lógicamente en una secuencia causal- a resultados a corto, medio y largo plazo (respectivamente, a productos, efectos e impactos).

Figura 1

Proyectos y programas de ayuda para el comercio: cadena de resultados

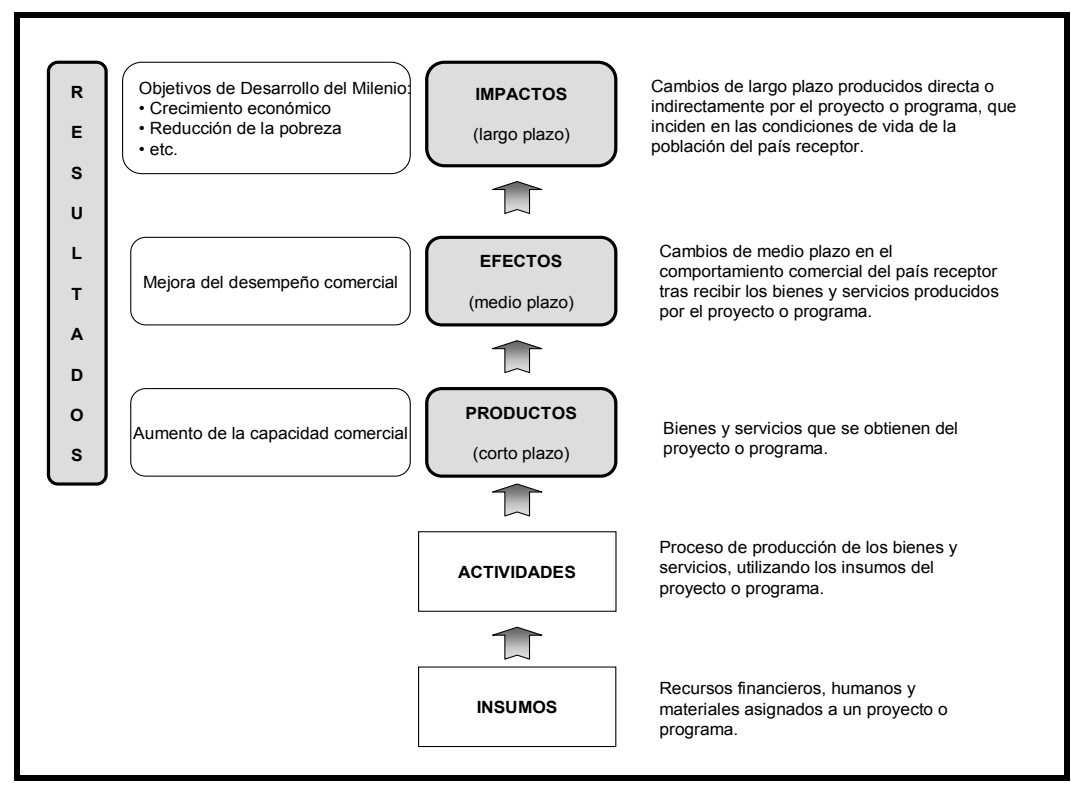

Fuente: Elaboración propia a partir de OCDE y Banco Mundial (2006), PNUD (2009), García-López y García-Moreno (2010) y OECD (2011b).

La medición periódica de los componentes de esta cadena de resultados es esencial para valorar si los proyectos de ApC están generando secuencialmente los cambios previstos y en caso de que no sea así, adoptar las medidas necesarias para volver a encauzar los proyectos en la senda adecuada. Para llevar a cabo esta medición, es necesario elaborar indicadores relevantes tanto de eficiencia como de eficacia. Los indicadores de eficiencia (esto es, de insumos, 
actividades y productos) se fijan a nivel micro, ligados estrechamente a las características específicas del proyecto. Por el contrario, los indicadores de eficacia (esto es, de efectos e impactos) se establecen a nivel macro del país receptor, con una conexión directa con el proyecto mucho menor. En la GpRD, estos indicadores de eficacia son indispensables para determinar si en última instancia el proyecto contribuye positivamente a la consecución de los objetivos más estratégicos de largo plazo.

Para diseñar estos indicadores, es necesario establecer cadenas de resultados que conecten nítidamente los objetivos micro de los proyectos con los objetivos macro de largo plazo que se pretenden conseguir con los mismos. Sin embargo, no es fácil establecer esta conexión en los proyectos de ApC porque previamente se requiere solventar tres importantes problemas (OECD, 2011b, pp. 73100). El primero es el de la limitada disposición de datos. Dado que la Iniciativa de la $\mathrm{ApC}$ es de reciente aplicación, se precisa más tiempo para acceder a un conjunto razonable de datos que facilite la elaboración de indicadores relevantes.

El segundo problema es el de la atribución. A medida que un proyecto de ApC se ejecuta a lo largo de la cadena de resultados desde el nivel micro al macro, resulta más difícil atribuir los cambios observados a dicho proyecto. Existe un gran número de factores externos que pueden influir en cada etapa de la cadena de resultados, tales como las características económicas, demográficas, sociales o institucionales del país receptor. En otras palabras, se carece de un enlace intermedio -el denominado missing middle- que permita aislar claramente la conexión directa entre los productos del proyecto y los impactos de largo plazo en el desarrollo del país receptor, esto es, la conexión entre los resultados micro de corto plazo y los resultados macro de más largo plazo (tales como, el crecimiento económico y la reducción de la pobreza).

El tercer y último problema es el del desfase temporal. Los efectos de los proyectos de ApC -como por ejemplo, aquéllos que financian infraestructurasno son inmediatos, sino que requieren un largo período de tiempo hasta que se materialicen en una mejora del desempeño comercial del país receptor. La ejecución de estos proyectos necesita tiempo y una vez finalizados, requieren aún tiempo adicional para que surtan los efectos deseados. Con este largo intervalo temporal transcurrido desde la provisión de la $\mathrm{ApC}$, resulta difícil valorar si la mejora en el desempeño comercial es o no el resultado directo de la ApC.

En suma, el principio de la GpRD ofrece un marco conceptual para promover la eficacia de la ApC, especialmente llamando la atención sobre la necesidad de realizar una gestión de la $\mathrm{ApC}$ que se materialice en resultados concretos de desarrollo. Sin embargo, la valoración del grado de aplicación de este principio está limitada por los problemas que plantea la medición regular de los componentes de la cadena de resultados. Como se argumenta en la próxima sección, 
esos problemas obligan a establecer enfoques metodológicos de valoración de los resultados de la $\mathrm{ApC}$ que se ajusten a la evidencia cuantitativa y cualitativa disponible.

\section{METODOLOGÍA DEL ESTUDIO}

El objetivo principal de la ApC es permitir a los PED "utilizar de forma más efectiva el comercio para promover el crecimiento, el desarrollo y la reducción de la pobreza y alcanzar sus objetivos de desarrollo, incluidos los Objetivos de Desarrollo del Milenio" (OMC, 2006, p. 4). En la medida en que los proyectos y programas de $\mathrm{ApC}$ contribuyan a la consecución de este objetivo, se puede considerar que los resultados de la Iniciativa de la ApC son satisfactorios y que dicha Iniciativa está aplicando adecuadamente la cadena de resultados en la que se basa el principio de la GpRD (véase la Figura 1). Sin embargo, existen importantes restricciones a la hora de identificar los indicadores para medir regularmente los componentes de dicha cadena y poder así, valorar el grado de influencia de la $\mathrm{ApC}$ en el cumplimiento del mencionado objetivo. Como se ha mostrado en la sección precedente, la limitada disposición de información cuantitativa unida a los problemas de la atribución y del desfase temporal hacen que por el momento, no sea posible contar con un conjunto significativo de datos e indicadores de resultados que sirvan de base para la aplicación de técnicas econométricas.

A pesar de los problemas señalados, un creciente número de países receptores y donantes está buscando la vía para elaborar indicadores de resultados o en su defecto, identificar los más relevantes entre los indicadores relacionados con el comercio ya existentes en la actualidad. Éste es el primer paso para poder posteriormente, armonizar los indicadores más significativos a partir de los cuales realizar el seguimiento y la evaluación de los proyectos de ApC, piezas claves en la GpRD. La armonización de los indicadores a nivel micro o de proyecto es muy dificil porque necesariamente estos indicadores han de ser diferentes con objeto de adecuarse a la gran diversidad de necesidades y prioridades específicas de cada proyecto. Sin embargo, la armonización de los indicadores a nivel macro o de país receptor es algo más factible, especialmente en el caso de los indicadores de efectos. Con esta visión, OECD (2011b, pp. 111-112) recopiló los principales indicadores de estas características generados en los últimos años y propuso un "menú de indicadores" como punto de partida para el debate sobre la armonización de los mismos a nivel global.

Teniendo en cuenta la limitada información disponible, se decidió acometer la valoración de los resultados de la Iniciativa de la ApC a partir de un doble enfoque metodológico: cuantitativo y cualitativo. El cuantitativo consistió en la selección de uno de los indicadores de efectos (resultados a medio plazo) propuestos por OECD (ibíd.) en el mencionado menú, específicamente: el Índice de 
Facilitación del Comercio (IFC) elaborado por el Foro Económico Mundial. Este indicador permitió tener una aproximación cuantitativa de algunos cambios potencialmente asociados con los proyectos y programas de $\mathrm{ApC}$, así como realizar una primera valoración de los mismos. Este enfoque fue completado con otro de naturaleza cualitativa basado en los relatos de experiencias concretas de ApC recopilados conjuntamente por la OMC y la Organización para la Cooperación y el Desarrollo Económico (OCDE). Estos relatos facilitaron la identificación de factores relevantes que condicionan la obtención de resultados.

Este doble enfoque cuantitativo y cualitativo se aplicó a una muestra de 17 países latinoamericanos: Argentina, Bolivia, Brasil, Chile, Colombia, Costa Rica, Ecuador, El Salvador, Guatemala, Honduras, México, Nicaragua, Panamá, Paraguay, Perú, Uruguay y Venezuela. Esta selección de países se hizo atendiendo a dos criterios. El primero fue que los países debían ubicarse geográficamente en América Latina; en otras palabras, no se tuvieron en cuenta los países del Caribe. El segundo criterio de selección fue que los países no debían de pertenecer a la Comunidad del Caribe, lo que llevó a excluir a tres países localizados geográficamente en América Latina (Belice, Surinam y Guyana). ${ }^{2}$

Con el fin de tener en cuenta la dimensión regional de la ApC, los países de la muestra se agruparon en tres subregiones: mesoamericana, andina y conosureña. La delimitación de estas subregiones no se realizó desde una perspectiva geográfica estricta, sino -como es habitual en estos casos- desde un enfoque geoeconómico más amplio. La región mesoamericana agrupó a Costa Rica, El Salvador, Guatemala, Honduras, México, Nicaragua y Panamá; la región andina incluyó a Bolivia, Colombia, Ecuador, Perú y Venezuela; y la región conosureña abarcó Argentina, Brasil, Chile, Paraguay y Uruguay.

La aplicación del enfoque metodológico propuesto requirió que previamente se identificaran las principales características de los flujos de ApC destinados a los países latinoamericanos de la muestra. Según OMC (2006, pp. 2-3), la ApC engloba a seis categorías conceptuales que pretenden tener en cuenta la gran variedad de actividades cubiertas por el comercio; en concreto: las políticas y reglamentos comerciales, el fomento del comercio, la infraestructura relacionada con el comercio, la creación de capacidad productiva, el ajuste relacionado con el comercio y las otras necesidades relacionadas con el comercio. La caracterización de los flujos de $\mathrm{ApC}$ en América Latina exigió establecer las categorías empíricas que más se aproximaran a estas seis categorías conceptuales.

\footnotetext{
${ }^{2}$ La razón de la exclusión de los países caribeños y de los miembros de la Comunidad del Caribe no sólo se fundamentó en el criterio geográfico, sino también en el hecho de que formaban parte del grupo de los países de África, Caribe y Pacífico (los denominados países ACP) hacia los que la Unión Europea -principal donante de ApC (si se considera conjuntamente la ApC de la Comisión Europea y la de los Estados Miembros)- mantiene una política de cooperación al desarrollo diferente a la aplicada a los países latinoamericanos.
} 
Para cuantificar las categorías empíricas, se decidió usar la base de datos del Sistema de Notificación de Acreedores (Creditor Reporting System, CRS) del CAD (OECD, a). Esta decisión se fundamentó en el hecho de que el CRS cubre alrededor del $90 \%$ de toda la $\mathrm{AOD},{ }^{3}$ ofreciendo series de datos comparables tanto entre donantes y países receptores como a lo largo del tiempo. Aunque esta base de datos incluye la mayor parte de la AOD, no proporciona datos que se ajusten con exactitud a las seis categorías conceptuales de ApC propuestas por la OMC. Siguiendo las directrices establecidas por el CAD para notificar los datos de ApC (OECD, 2008), fue posible obtener las siguientes cuatro aproximaciones empíricas a dichas categorías conceptuales: políticas y reglamentos comerciales, infraestructura económica, creación de capacidad productiva y ajuste relacionado con el comercio. ${ }^{4}$

El período seleccionado para la caracterización de los flujos de ApC en América Latina fue el comprendido entre 2002 (año posterior al lanzamiento de la Ronda de Doha) y 2010 (último año para el que existen datos homogéneos comparables). Con objeto de realizar un análisis comparativo de la tendencia de los flujos de ApC, se tomó el período 2002-2005 como período base, ya que es el comprendido entre el año posterior al comienzo de la Ronda de Doha y el año de la puesta en marcha de la Iniciativa de la ApC. Se llevaron a cabo comparaciones de las tendencias del período base con las del período posterior de 20062010. Para poder captar el valor real de los flujos de ApC a lo largo del período de estudio, los compromisos y desembolsos de ApC se expresaron en millones de dólares constantes de 2009.

Las siguientes tres secciones recogen los resultados de la aplicación de la metodología presentada. La sección 4 se destina a caracterizar los flujos de ApC en América Latina, la sección 5 se dedica al enfoque cuantitativo basado en el IFC y la sección 6 se centra en el enfoque cualitativo fundamentado en los relatos de experiencias concretas de ApC en América Latina.

\footnotetext{
${ }^{3}$ Sobre el porcentaje de cobertura de esta base de datos, véase la página web de la OCDE en:

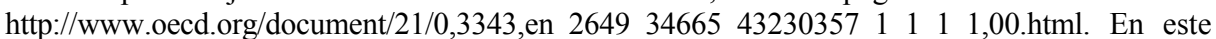
artículo se utilizan únicamente los datos de $\overline{\mathrm{A} O D}$ registrados por el $\overline{\mathrm{C}} \overline{\mathrm{AD}} \overline{\mathrm{de}}$ la $\mathrm{OCDE}$.

${ }^{4}$ La cuantificación de los flujos de ApC hacia América Latina ha de ser considerada como una aproximación y ha de ser interpretada con precaución. Por el momento, resulta difícil medir con precisión los flujos de ApC porque las categorías conceptuales no se corresponden con exactitud con las categorías empíricas ofrecidas por la base de datos del CRS de la OCDE. Asimismo, en algunos casos -como los de infraestructura económica y creación de capacidad productivalas categorías empíricas son excesivamente amplias -sin diferenciar los proyectos relacionados con el comercio de los que no lo están- y por ello, se tiende a sobrestimar su valor. Una justificación más amplia de las cuatro aproximaciones empíricas se presenta en Rueda-Junquera y Gozalo-Delgado (2011, pp. 42-45).
} 


\section{PRINCIPALES TENDENCIAS DE LA AYUDA PARA EL COMERCIO EN AMÉRICA LATINA}

Los flujos mundiales de $\mathrm{ApC}$ han experimentado un notable crecimiento desde el lanzamiento de la Iniciativa en 2005. El valor medio de los compromisos mundiales de ApC se incrementó en términos reales desde 24.746,5 millones de dólares anuales en el período 2002-2005 hasta 35.952,2 millones de dólares anuales en el período 2006-2010, lo que supuso un aumento del 45,3\%. ${ }^{5}$ No obstante, en los dos últimos años se aprecia una desaceleración en la tasa de crecimiento de la $\mathrm{ApC}$, lo que podría estar mostrando los primeros efectos negativos de la crisis económica internacional sobre los flujos de ApC.

América Latina también ha participado de estos crecientes recursos. Los compromisos de $\mathrm{ApC}$ canalizados hacia los 17 países latinoamericanos de la muestra aumentaron en términos reales desde un promedio de 1.318,2 millones anuales de dólares en el período base de 2002-2005 hasta 1.815,3 millones de dólares en el período 2006-2010, lo que representó un incremento del 37,7\% (véase la Tabla 1). A pesar de este incremento, América Latina no es una región privilegiada en el reparto mundial de los flujos de ApC. Su relativamente mayor nivel de renta per cápita -la región está conformada mayoritariamente por países de renta media- y su menor población con respecto a regiones como Asia y África, son dos factores que explican su posición marginal. ${ }^{6}$ De hecho, ha recibido un reducido porcentaje del total mundial de compromisos de $\mathrm{ApC}$-en torno al $7 \%$ en los dos períodos considerados ${ }^{7}$-, siendo la tercera región receptora, por detrás de Asia y África.

Como muestra la Tabla 1, la distribución de los compromisos de ApC entre los 17 países latinoamericanos considerados en la investigación, se ajusta a las diferencias de renta existentes entre ellos. Con las excepciones de Brasil y México, los países que más $\mathrm{ApC}$ reciben son los nueve países clasificados como países de renta media baja. En el período de referencia 2002-2005, este grupo de países acaparó el $80,2 \%$ del total de la ApC comprometida con América Latina, mientras que en el período 2006-2010, su importancia relativa descendió ligeramente hasta el $76,4 \%$. Nicaragua y Bolivia son los dos países de renta media baja que más ApC han recibido en promedio durante 2006-2010, seguidos de Colombia, El Salvador, Perú, Honduras, Paraguay, Ecuador y Guatemala. Con la excepción de Bolivia y Honduras, el resto de los países ha visto

\footnotetext{
${ }^{5}$ Los valores y porcentajes mencionados en esta sección que no aparecen en las tablas, se calcularon a partir de OECD (a).

${ }^{6}$ Sobre la Iniciativa de la ApC en América Latina, véanse BID (2006 y 2007), ECLAC (2009), OMC/BID (2009), OMC/BID/OCDE (2011) y Rueda-Junquera y Gozalo-Delgado (2011).

${ }^{7}$ Los compromisos de ApC hacia América Latina y el Caribe han representado un 6,9\% en el período 2002-2005 y un 7,0\% en el período 2006-2010 (OECD, a).
} 
incrementado el flujo medio de ApC comprometida con respecto al período 2002-2005.

\section{Tabla 1}

Flujos de ayuda para el comercio hacia América Latina: compromisos, 2002-2010 (en millones de dólares constantes de 2009 y en porcentajes)

\begin{tabular}{|c|c|c|c|c|}
\hline \multirow{2}{*}{ Subregión / País / Grupo de renta ${ }^{1}$} & \multicolumn{2}{|c|}{$2002-2005$} & \multicolumn{2}{|c|}{$2006-2010$} \\
\hline & Media & $\begin{array}{c}\% \text { de } \\
\text { ApC total }\end{array}$ & Media & $\begin{array}{c}\% \text { de } \\
\text { ApC total }\end{array}$ \\
\hline SUBREGIÓN MESOAMERICANA & 526,28 & 39,92 & 661,10 & 36,42 \\
\hline Costa Rica (PRMA) & 51,52 & 3,91 & 19,59 & 1,08 \\
\hline El Salvador (PRMB) & 29,61 & 2,25 & 154,26 & 8,50 \\
\hline Guatemala (PRMB) & 30,14 & 2,29 & 68,67 & 3,78 \\
\hline Honduras (PRMB) & 182,27 & 13,83 & 113,76 & 6,27 \\
\hline México (PRMA) & 26,81 & 2,03 & 77,39 & 4,26 \\
\hline Nicaragua (PRMB) & 195,51 & 14,83 & 213,44 & 11,76 \\
\hline Panamá (PRMA) & 10,41 & 0,79 & 14,00 & 0,77 \\
\hline SUBREGIÓN ANDINA & 518,54 & 39,34 & 581,91 & 32,06 \\
\hline Bolivia (PRMB) & 253,69 & 19,25 & 198,03 & 10,91 \\
\hline Colombia (PRMB) & 82,23 & 6,24 & 164,70 & 9,07 \\
\hline Ecuador (PRMB) & 51,07 & 3,87 & 68,75 & 3,79 \\
\hline Perú (PRMB) & 129,02 & 9,79 & 148,70 & 8,19 \\
\hline Venezuela (PRMA) & 2,53 & 0,19 & 1,72 & 0,10 \\
\hline SUBREGIÓN CONOSUREÑA & 165,08 & 12,52 & 365,10 & 20,11 \\
\hline Argentina (PRMA) & 48,08 & 3,65 & 36,18 & 1,99 \\
\hline Brasil (PRMA) & 52,76 & 4,00 & 183,61 & 10,11 \\
\hline Chile (PRMA) & 40,57 & 3,08 & 40,84 & 2,25 \\
\hline Paraguay (PRMB) & 17,29 & 1,31 & 97,53 & 5,37 \\
\hline Uruguay (PRMA) & 6,38 & 0,48 & 6,94 & 0,38 \\
\hline PROGRAMAS REGIONALES & 108,32 & 8,22 & 207,23 & 11,42 \\
\hline América del Norte y Central & 66,95 & 5,08 & 112,70 & 6,21 \\
\hline América del Sur & 41,37 & 3,14 & 94,53 & 5,21 \\
\hline AMÉRICA LATINA & $1.318,22$ & 100,00 & $1.815,35$ & 100,00 \\
\hline
\end{tabular}

1 Para identificar el grupo de renta al que pertenece cada país, se tomó como referencia la lista de países receptores de ayuda oficial al desarrollo elaborada por el Comité de Ayuda al Desarrollo de la Organización para la Cooperación y el Desarrollo Económico para los ejercicios de notificación 2009 y 2010. Los acrónimos utilizados son PRMB: País de Renta Media Baja (Renta Nacional Bruta por habitante comprendida entre $936 \$$ y $3.705 \$$ en 2007) y PRMA: País de Renta Media Alta (Renta Nacional Bruta por habitante comprendida entre $3.705 \$$ y $11.455 \$$ en 2007).

${ }^{2}$ Porcentaje de la ayuda para el comercio (ApC) total

Fuente: Elaboración propia a partir de OECD (a).

Paralelamente, los ocho países restantes de la región latinoamericana -clasificados como de renta media alta- ocupan los últimos lugares de la clasificación regional de la ApC comprometida. De ellos, Brasil es el país hacia el que más ApC se ha canalizado en el período 2006-2010, debido singularmente al gran incremento registrado en 2009 y 2010. Tras él, se sitúa México, Chile, Argentina, Costa Rica, Panamá, Uruguay y Venezuela. Con respecto al período de 
referencia, el volumen de ayuda comprometida ha aumentado en todos los países con las excepciones de Argentina, Costa Rica y Venezuela.

Por subregiones, se mantiene el resultado obtenido a nivel de país; esto es, las subregiones con un mayor número de países de renta media baja son las más privilegiadas en el reparto de los flujos de ApC (véase la Tabla 1). En el período base, el mayor porcentaje de los compromisos de ApC hacia América Latina lo recibió la subregión mesoamericana $(39,9 \%)$, seguida muy de cerca por la subregión andina $(39,3 \%)$ y a mayor distancia por la subregión conosureña $(12,5 \%)$ y los programas regionales $(8,2 \%)$. En el período 2006-2010, estas posiciones relativas se han mantenido con algunas variaciones en los porcentajes. En todos los casos -subregiones y programas regionales-, se aprecia un ascenso del volumen medio de compromisos de $\mathrm{ApC}$, lo que parece indicar que todas las subregiones se han beneficiado de la expansión de la $\mathrm{ApC}$ en el período 2006-2010.

La distribución de la ApC entre las cuatro categorías empíricas consideradas -políticas y reglamentos comerciales, infraestructura económica, creación de capacidad productiva y ajuste relacionado con el comercio- no se ha visto alterada durante el período de investigación en lo que se refiere al orden de importancia de cada una de ellas. Sin embargo, en términos porcentuales, ha experimentado algunas variaciones significativas (véase la Tabla 2). En primer lugar, la categoría de creación de capacidad productiva ha acaparado el mayor porcentaje en el total de la ApC comprometida en América Latina para los dos períodos analizados. No obstante, se observa una importante reducción en dicho porcentaje desde el $70,2 \%$ del total de la ApC en el período base hasta el 57,7\% en el período 2006-2010. En segundo lugar, la categoría de infraestructura económica ha aumentado su peso relativo desde el $26,2 \%$ en el período base hasta el $37,9 \%$. En tercer lugar y a bastante distancia, la categoría de políticas y reglamentos comerciales mantuvo un peso reducido del $4,4 \%$ en el período 20062010. En cuarto y último lugar, la categoría de ajuste relacionado con el comercio presentó un valor nulo en todos los países de la muestra. ${ }^{8}$

Si se compara con la distribución sectorial a nivel mundial, se aprecia una diferencia fundamental en América Latina: la creación de capacidad productiva es la principal categoría de la $\mathrm{ApC}$ comprometida con esta región, mientras que la categoría de infraestructura económica ocupa la primera posición a nivel mundial. Este hecho confirma el resultado obtenido en el segundo y tercer Examen Global de la ApC (OECD/WTO, 2009 y 2011), según el cual la ApC en los países de renta baja se destina principalmente a mejorar su deficiente infraestructura económica, mientras que en los países de renta media -que tienen

\footnotetext{
${ }^{8}$ La causa principal del valor nulo en esta categoría de ajuste relacionado con el comercio se atribuye a su reciente inclusión en 2008.
} 
mejor cubiertas sus necesidades de infraestructura- se canaliza en mayor medida hacia la creación de capacidad productiva.

\section{Tabla 2}

América Latina: compromisos de ayuda para el comercio por categorías, 2002-2010 (en millones de dólares constantes de 2009 y en porcentajes)

\begin{tabular}{|c|c|c|c|c|}
\hline \multirow[b]{2}{*}{ Subregión / Categoría } & \multicolumn{2}{|c|}{$2002-2005$} & \multicolumn{2}{|c|}{$2006-2010$} \\
\hline & media & $\begin{array}{c}\% \text { de ApC } \\
\text { total }\end{array}$ & media & $\begin{array}{c}\% \text { de ApC } \\
\text { total }^{1}\end{array}$ \\
\hline \multicolumn{5}{|l|}{ SUBREGIÓN MESOAMERICANA } \\
\hline Políticas y reglamentos comerciales & 11,87 & 2,26 & 34,00 & 5,14 \\
\hline Infraestructura económica & 198,73 & 37,76 & 328,96 & 49,76 \\
\hline Creación de capacidad productiva & 315,68 & 59,98 & 298,15 & 45,10 \\
\hline Ajuste relacionado con el comercio & 0,00 & 0,00 & 0,00 & 0,00 \\
\hline Ayuda para el comercio, total & 526,28 & 100,00 & 661,10 & 100,00 \\
\hline \multicolumn{5}{|l|}{ SUBREGIÓN ANDINA } \\
\hline Políticas y reglamentos comerciales & 18,12 & 3,49 & 15,97 & 2,74 \\
\hline Infraestructura económica & 106,24 & 20,49 & 115,54 & 19,86 \\
\hline Creación de capacidad productiva & 394,18 & 76,02 & 450,40 & 77,40 \\
\hline Ajuste relacionado con el comercio & 0,00 & 0,00 & 0,00 & 0,00 \\
\hline Ayuda para el comercio, total & 518,54 & 100,00 & 581,91 & 100,00 \\
\hline \multicolumn{5}{|l|}{ SUBREGIÓN CONOSUREÑA } \\
\hline Políticas y reglamentos comerciales & 8,83 & 5,35 & 4,59 & 1,26 \\
\hline Infraestructura económica & 10,89 & 6,60 & 177,46 & 48,60 \\
\hline Creación de capacidad productiva & 145,36 & 88,05 & 183,05 & 50,14 \\
\hline Ajuste relacionado con el comercio & 0,00 & 0,00 & 0,00 & 0,00 \\
\hline Ayuda para el comercio, total & 165,08 & 100,00 & 365,10 & 100,00 \\
\hline \multicolumn{5}{|l|}{ AMÉRICA LATINA } \\
\hline Políticas y reglamentos comerciales & 47,05 & 3,57 & 79,56 & 4,38 \\
\hline Infraestructura económica & 345,93 & 26,24 & 687,76 & 37,89 \\
\hline Creación de capacidad productiva & 925,24 & 70,19 & $1.048,04$ & 57,73 \\
\hline Ajuste relacionado con el comercio & 0,00 & 0,00 & 0,00 & 0,00 \\
\hline Ayuda para el comercio, total & $1.318,22$ & 100,00 & $1.815,35$ & 100,00 \\
\hline
\end{tabular}

${ }^{1}$ Porcentaje de la ayuda para el comercio (ApC) total.

Fuente: Elaboración propia a partir de OECD (a).

La distribución sectorial de la ApC en América Latina muestra también algunas divergencias entre las subregiones contempladas en el estudio (véase la Tabla 2). La creación de capacidad productiva es la principal categoría en las tres subregiones durante el período de referencia, especialmente en la conosureña $(88,1 \%$ del total) y en la andina $(76 \%)$, y en menor medida, en la mesoamericana $(60 \%)$. Sin embargo, en el período 2006-2010 este patrón se ve alterado parcialmente, ya que la infraestructura económica pasa a ser la principal categoría en la subregión mesoamericana $(49,8 \%)$ y aumenta significativa- 
mente en la subregión conosureña $(48,6 \%) .{ }^{9}$ Por lo que respecta a la categoría de políticas y reglamentos comerciales, su peso es muy pequeño en las tres subregiones y en los dos períodos considerados (en ningún caso, representa más del el 5,35\% del total).

\section{ENFOQUE CUANTITATIVO: EL ÍNDICE DE FACILITACIÓN DEL COMERCIO}

Entre los índices disponibles para medir y comparar los obstáculos al comercio internacional, destaca el IFC elaborado por el Foro Económico Mundial. Este índice recoge los principales componentes de la facilitación del comercio por medio de cuatro subíndices -acceso al mercado, administración aduanera, infraestructura de transporte y comunicaciones, y clima de negocios- que a su vez, se obtienen a partir de nueve pilares facilitadores del comercio internacional (véase la Figura 2). ${ }^{10}$

Como demostró Lawrence et al. (2009, pp. 33-35), el IFC tiene un significativo poder explicativo en relación con el desempeño comercial de un país; así por ejemplo, un incremento del $1 \%$ en el valor del IFC de un país exportador está asociado con un aumento del 1,7\% de sus exportaciones. El análisis de los valores del IFC permite obtener aproximaciones razonables del desempeño comercial de un país. Si el valor del IFC ha aumentado en los 17 países latinoamericanos de la muestra, será un indicio de que el aumento de los flujos de $\mathrm{ApC}$ hacia estos países puede haber contribuido positivamente a obtener resultados, especialmente en términos de mejora de su capacidad comercial.

El IFC se elabora desde 2008 para una muestra de países que ha ido ampliándose desde el primer informe. La base metodológica del mismo ha sufrido algunos cambios, siendo el más importante el que tuvo lugar en 2009 al incluir la dimensión exportadora. ${ }^{11}$ Debido a este cambio, la investigación analizó y comparó los resultados del IFC publicados a partir de dicho año, esto es, los de

${ }^{9}$ El inusual aumento de la importancia relativa de la infraestructura económica en el período 2006-2010 en una región como la conosureña -constituida mayoritariamente por países de renta media alta- parece ser el resultado de un significativo incremento coyuntural de los compromisos de ApC destinados a Brasil en 2009 y 2010 (OECD, a). Asimismo, es posible que el valor de la categoría de infraestructura económica en este país esté algo sobrestimado y no incluya únicamente los proyectos de cooperación en infraestructura utilizada para el comercio. Como se ha justificado en la sección 3, esta potencial sobrestimación se debe a que la aproximación empírica a la categoría conceptual de infraestructura económica no permite diferenciar los proyectos relacionados con el comercio de los que no lo están.

${ }^{10}$ Para más información sobre la composición y metodología del IFC, véanse los diferentes informes publicados por el Foro Económico Mundial y disponibles en su página web en la siguiente dirección: http://www.weforum.org.

${ }^{11}$ Un análisis detallado de los cambios realizados en la metodología del índice se encuentra en WEF (2009, p. 9), WEF (2010, p. 8) y WEF (2012, p. 8). 
2009, 2010 y 2012. El valor del índice oscila en una escala de 1 a 7, siendo el valor 1 el peor resultado que puede obtener un país en la facilitación del comercio y el valor 7 el mejor resultado que puede alcanzar un país en esta clasificación (WEF, 2012, pp. 29-30).

Figura 2

Composición del Índice de Facilitación del Comercio: subíndices y pilares

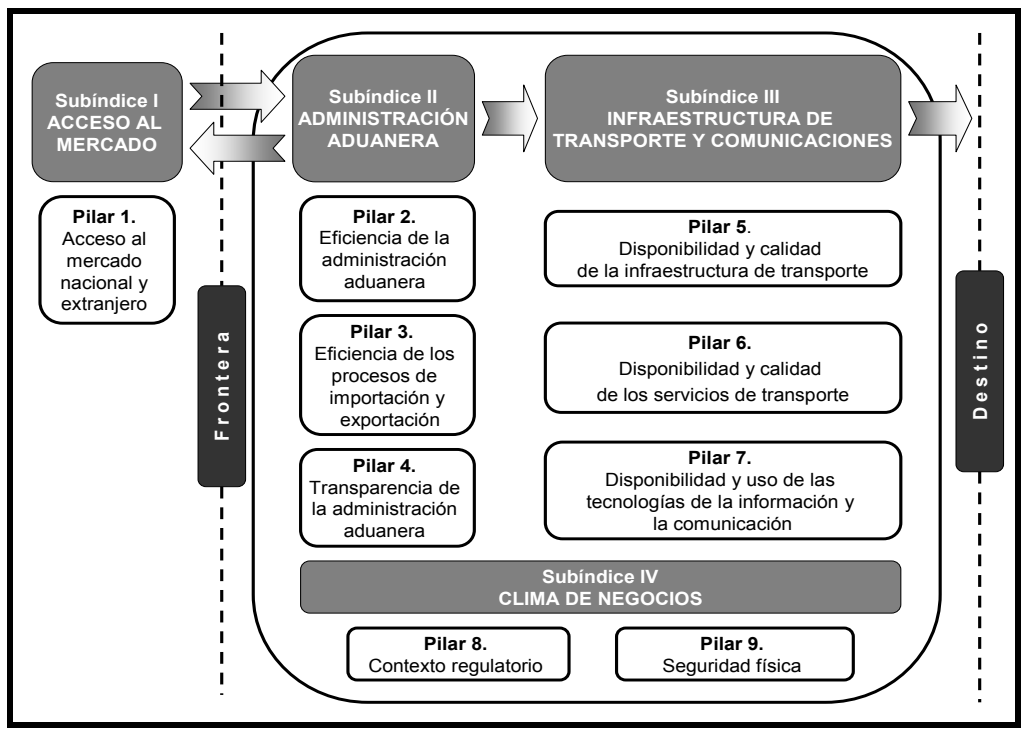

Fuente: Elaboración propia a partir de WEF (2012, Figura 1, p. 7).

La Tabla 3 muestra el valor del IFC para los 17 países latinoamericanos y las tres subregiones de la investigación. En los tres años examinados, Chile aparece como el país con el mayor valor del índice y Venezuela como el país con el menor valor. En 2012 Chile alcanza un valor de 5,12 y Venezuela un valor de 2,95 ; mientras que a nivel mundial y a efectos comparativos, Singapur ocupa el primer puesto con un valor de 6,14 y Chad se sitúa en el último puesto con un valor de 2,63 (WEF, 2012, Cuadro 1, p. 9). Por subregiones, la conosureña y la mesoamericana alcanzaron los mayores valores del IFC en los tres años examinados, situándose siempre por encima de la media regional. En 2012, el valor promedio del IFC en las subregiones conosureña y mesoamericana fue respectivamente, de 4,11 y 4,04 -superando el valor medio regional $(3,95)$-, en tanto que el de la subregión andina fue de 3,71. 
Tabla 3

América Latina: valor del Índice de Facilitación del Comercio, 2009-2012 (variación en porcentaje)

\begin{tabular}{|l|c|c|c|c|}
\hline & $\begin{array}{c}\text { Valor del } \\
\text { IFC }\end{array}$ & $\begin{array}{c}\text { Valor del } \\
\text { IFC } \\
\mathbf{2 0 0 9}\end{array}$ & $\begin{array}{c}\text { Valor del } \\
\text { IFC }\end{array}$ & $\begin{array}{c}\text { Variación del IFC } \\
\mathbf{2 0 0 9}-\mathbf{2 0 1 2} \text { (\%) }\end{array}$ \\
\hline Costa Rica & 4,36 & 4,45 & 4,41 & 1,15 \\
El Salvador & 4,00 & 4,16 & 3,99 & $-0,25$ \\
Guatemala & 3,97 & 3,97 & 3,90 & $-1,76$ \\
Honduras & 3,80 & 3,98 & 3,89 & 2,37 \\
México & 3,74 & 4,04 & 4,08 & 9,09 \\
Nicaragua & 3,71 & 3,85 & 3,83 & 3,23 \\
Panamá & 4,06 & 4,12 & 4,16 & 2,46 \\
SUBREGIÓN MESOAMERICANA & 3,95 & 4,08 & 4,04 & 2,28 \\
\hline Bolivia & 3,55 & 3,59 & 3,68 & 3,66 \\
Colombia & 3,61 & 3,72 & 3,78 & 4,71 \\
Ecuador & 3,41 & 3,74 & 3,83 & 12,32 \\
Perú & 3,81 & 4,04 & 4,31 & 13,12 \\
Venezuela & 2,84 & 3,04 & 2,95 & 3,87 \\
SUBREGIÓN ANDINA & 3,44 & 3,63 & 3,71 & 7,85 \\
\hline Argentina & 3,46 & 3,64 & 3,68 & 6,36 \\
Brasil & 3,58 & 3,76 & 3,79 & 5,87 \\
Chile & 4,96 & 5,06 & 5,12 & 3,23 \\
Paraguay & 3,39 & 3,53 & 3,53 & 4,13 \\
Uruguay & 4,18 & 4,29 & 4,44 & 6,22 \\
SUBREGIÓN CONOSUREÑ & 3,91 & 4,06 & 4,11 & 5,12 \\
\hline AMÉRICA LATINA & 3,79 & 3,94 & 3,95 & 4,22 \\
\hline
\end{tabular}

IFC: Índice de Facilitación del Comercio.

Fuente: Elaboración propia a partir de $\operatorname{WEF}$ (2009, pp. 12 y 13), $\operatorname{WEF}(2010$, p. 9) y WEF (2012, p. 9).

Con respecto al valor del IFC de 2009, la mayoría de los países de la región latinoamericana experimentaron un aumento de su índice en 2012, siendo El Salvador y Guatemala las dos únicas excepciones con leves reducciones de $0,25 \%$ y $1,76 \%$, respectivamente (véase la Tabla 3 ). No obstante, la tasa de variación del IFC entre 2009 y 2012 presentó diferencias entre los distintos países y subregiones. Los países que experimentaron un mayor incremento fueron Perú $(13,12 \%)$ y Ecuador $(12,32 \%)$, mientras que los que tuvieron un menor aumento fueron Costa Rica $(1,15 \%)$ y Honduras $(2,37 \%)$. En el caso de las subregiones, se aprecia un incremento en el valor del IFC para las tres subregiones en 2012 en relación al valor de 2009 , con tasas de variación del $7,85 \%$ en la andina, $5,12 \%$ en la conosureña y $2,28 \%$ en la mesoamericana. Este aumento del valor del IFC en la práctica totalidad de los países latinoamericanos y en las tres subregiones es un primer indicio del potencial efecto positivo que la ApC puede haber tenido en la mejora de la capacidad comercial de los países receptores de la región.

Los valores de los distintos subíndices y pilares que componen el IFC se recogen en las Tablas 4, 5 y 6 . Las tres subregiones alcanzaron su valor más alto en el primer subíndice acceso al mercado. Su valor aumentó en 2012 respecto a 
2009 en las subregiones mesoamericana y andina y se redujo ligeramente en la subregión conosureña. La buena posición de este subíndice en el IFC es producto de las mejoras de acceso a mercados promovidas por los acuerdos de liberalización comercial firmados tanto a nivel intrarregional (en el marco de los procesos de integración subregional impulsados) como a nivel extrarregional (en el marco de los acuerdos bilaterales y plurilaterales de libre comercio suscritos). Este contexto refleja la apuesta decidida de la mayor parte de los países latinoamericanos por incorporar el comercio a sus estrategias nacionales de desarrollo, lo que es un factor clave para que la Iniciativa de la ApC haya podido producir resultados positivos en la región.

Tabla 4

Subregión mesoamericana: valor del Índice de Facilitación del Comercio, 2009-2012

\begin{tabular}{|c|c|c|c|}
\hline Índice / Subíndice / Pilar & 2009 & 2010 & 2012 \\
\hline ÍNDÍCE DE FACILITACIÓN DEL COMERCIO & 3,95 & 4,08 & 4,04 \\
\hline Subíndice I. Acceso al mercado & 4,89 & 5,10 & 4,98 \\
\hline P1. Acceso al mercado nacional y extranjero & 4,89 & 5,10 & 4,98 \\
\hline Subíndice II. Administración aduanera & 3,88 & 4,04 & 3,97 \\
\hline P2. Eficiencia de la administración aduanera & 3,45 & 4,04 & 3,97 \\
\hline P3. Eficiencia de los procesos de importación y exportación & 4,64 & 4,68 & 4,73 \\
\hline P4. Transparencia de la administración aduanera & 3,56 & 3,39 & 3,20 \\
\hline Subíndice III. Infraestructura de transporte y comunicaciones & 3,12 & 3,40 & 3,57 \\
\hline P5. Disponibilidad y calidad de la infraestructura de transporte & 3,40 & 3,90 & 3,93 \\
\hline P6. Disponibilidad y calidad de los servicios de transporte & 3,11 & 3,35 & 3,19 \\
\hline P7. Disponibilidad y uso de las TICs & 2,86 & 2,96 & 3,59 \\
\hline Subíndice IV. Clima de negocios & 3,90 & 3,78 & 3,64 \\
\hline P8. Contexto regulatorio & 3,79 & 3,64 & 3,59 \\
\hline P9. Seguridad física & 4,02 & 3,92 & 3,68 \\
\hline
\end{tabular}

P: Pilar; TICs: Tecnologías de la información y la comunicación.

1 El valor del Índice de Facilitación del Comercio (IFC) se obtiene a partir de la media de los valores de los IFC de los países que forman la subregión mesoamericana.

Fuente: Elaboración propia a partir de WEF (2009, Cuadros 1-5, pp. 12-21), WEF (2010, Cuadros 2-6, pp. 10-19) y WEF (2012, Cuadros 2-6, pp. 10-19).

El valor del segundo subíndice administración aduanera aumentó en las tres subregiones en 2012 respecto al obtenido en 2009. El aumento del valor de este subíndice se asienta en la mejora de la eficiencia de la administración aduanera (pilar 2), dado que se produce un leve retroceso en la mayoría de países en la eficiencia de los procesos de importación y exportación (pilar 3) y en la transparencia de la administración aduanera (pilar 4). Como se acaba de indicar, la mayor parte de los países latinoamericanos están inmersos en la aplicación de acuerdos de liberalización comercial, lo que les obliga a modernizar sus administraciones aduaneras adaptándolas a los cambios requeridos para establecer una zona de libre comercio y/o una unión aduanera. Todo ello ha conducido a una mejora en la eficiencia de la administración aduanera (pilar 2), a la que 
probablemente haya contribuido la ApC destinada a la categoría de políticas y reglamentos comerciales. No obstante, el proceso de modernización aduanera deberá completarse en los próximos años a medida que se profundice en la aplicación de los acuerdos comerciales suscritos (lo que redundará en una mejora de los pilares 3 y 4 ).

\section{Tabla 5}

Subregión andina: valor del Índice de Facilitación del Comercio, 2009-2012

\begin{tabular}{|c|c|c|c|}
\hline Índice / Subíndice / Pilar & 2009 & 2010 & 2012 \\
\hline ÍNDÍCE DE FACILITACIÓN DEL COMERCIO & 3,44 & 3,63 & 3,71 \\
\hline Subíndice I. Acceso al mercado & 4,36 & 4,59 & 4,54 \\
\hline P1. Acceso al mercado nacional y extranjero & 4,36 & 4,59 & 4,54 \\
\hline Subíndice II. Administración aduanera & 3,22 & 3,41 & 3,49 \\
\hline P2. Eficiencia de la administración aduanera & 2,71 & 3,56 & 3,74 \\
\hline P3. Eficiencia de los procesos de importación y exportación & 3,86 & 3,78 & 3,74 \\
\hline P4. Transparencia de la administración aduanera & 3,07 & 2,89 & 3,00 \\
\hline Subíndice III. Infraestructura de transporte y comunicaciones & 2,92 & 3,29 & 3,44 \\
\hline P5. Disponibilidad y calidad de la infraestructura de transporte & 3,07 & 3,66 & 3,56 \\
\hline P6. Disponibilidad y calidad de los servicios de transporte & 3,01 & 3,23 & 3,26 \\
\hline P7. Disponibilidad y uso de las TICs & 2,66 & 2,99 & 3,50 \\
\hline Subíndice IV. Clima de negocios & 3,28 & 3,22 & 3,37 \\
\hline P8. Contexto regulatorio & 2,98 & 2,95 & 3,23 \\
\hline P9. Seguridad física & 3,58 & 3,49 & 3,51 \\
\hline
\end{tabular}

P: Pilar; TICs: Tecnologías de la información y la comunicación.

${ }^{1}$ El valor del Índice de Facilitación del Comercio (IFC) se obtiene a partir de la media de los valores de los IFC de los países que forman la subregión andina.

Fuente: Elaboración propia a partir de WEF (2009, Cuadros 1-5, pp. 12-21), WEF (2010, Cuadros 2-6, pp. 10-19) y WEF (2012, Cuadros 2-6, pp. 10-19).

Tabla 6

Subregión conosureña: valor del Índice de Facilitación del Comercio, 2009-2012 ${ }^{1}$

\begin{tabular}{|c|c|c|c|}
\hline Índice / Subíndice / Pilar & 2009 & 2010 & 2012 \\
\hline ÍNDÍCE DE FACILITACIÓN DEL COMERCIO & 3,91 & 4,06 & 4,11 \\
\hline Subíndice I. Acceso al mercado & 4,47 & 4,48 & 4,41 \\
\hline P1. Acceso al mercado nacional y extranjero & 4,47 & 4,48 & 4,41 \\
\hline Subíndice II. Administración aduanera & 3,90 & 4,03 & 4,04 \\
\hline P2. Eficiencia de la administración aduanera & 3,40 & 4,07 & 4,10 \\
\hline P3. Eficiencia de los procesos de importación y exportación & 4,40 & 4,21 & 4,10 \\
\hline P4. Transparencia de la administración aduanera & 3,91 & 3,80 & 3,91 \\
\hline Subíndice III. Infraestructura de transporte y comunicaciones & 3,24 & 3,57 & 3,75 \\
\hline P5. Disponibilidad y calidad de la infraestructura de transporte & 3,12 & 3,74 & 3,65 \\
\hline P6. Disponibilidad y calidad de los servicios de transporte & 3,30 & 3,51 & 3,49 \\
\hline P7. Disponibilidad y uso de las TICs & 3,29 & 3,47 & 4,11 \\
\hline Subíndice IV. Clima de negocios & 4,06 & 4,14 & 4,25 \\
\hline P8. Contexto regulatorio & 3,63 & 3,61 & 3,82 \\
\hline P9. Seguridad física & 4,48 & 4,68 & 4,69 \\
\hline
\end{tabular}

P: Pilar; TICs: Tecnologías de la información y la comunicación.

1 El valor del Índice de Facilitación del Comercio (IFC) se obtiene a partir de la media de los valores de los IFC de los paises que forman la subregión conosureña.

Fuente: Elaboración propia a partir de WEF (2009, Cuadros 1-5, pp. 12-21), WEF (2010, Cuadros 2-6, pp. 10-19) y WEF (2012, Cuadros 2-6, pp. 10-19). 
En lo que respecta al tercer subíndice infraestructura de transporte y comunicaciones, el valor aumentó en las tres subregiones y en este caso, la evolución fue positiva en los tres pilares que lo componen. Pese a esta evolución positiva, el examen de la posición relativa de los países de la región a nivel mundial reflejó un notable retraso en esta materia (WEF, 2012, pp. 16 y 17). Tanto los gobiernos latinoamericanos como las instituciones multilaterales -especialmente, el Banco Interamericano de Desarrollo (BID)- son conscientes de este retraso y por ello, han promovido iniciativas -como el Proyecto Mesoamérica y la Iniciativa para la Integración de la Infraestructura Regional Sudamericanapara fortalecer la infraestructura física y logística de la región. La ApC -que tiene entre sus objetivos impulsar los proyectos de infraestructura- se ha adaptado sin problemas a estas iniciativas, favoreciendo su expansión. Esto podría explicar -como se ha puesto de manifiesto en la sección 4- que la categoría de infraestructura económica se haya convertido en el principal destino de los compromisos de $\mathrm{ApC}$ en la subregión mesoamericana en los últimos años y que haya aumentado significativamente en la subregión conosureña. Por ejemplo, la Red Internacional de Carreteras Mesoamericanas -financiada parcialmente a través de los flujos de ApC en el marco del Proyecto Mesoamérica- sería responsable de parte de los avances en la facilitación del comercio percibidos en la subregión a través de la mejora en la disponibilidad y calidad de la infraestructura y de los servicios de transporte terrestre. En este contexto, es razonable esperar que los flujos de $\mathrm{ApC}$ hayan contribuido positivamente a mejorar el subíndice de infraestructura del IFC de los países latinoamericanos.

El valor del cuarto y último subíndice clima de negocios se incrementa en la subregión conosureña y en menor medida, en la subregión andina. En este ámbito, destaca el retroceso experimentado en la subregión mesoamericana tanto en contexto regulatorio (pilar 8) como en seguridad física (pilar 9), poniendo en evidencia el grave problema de debilidad institucional e inseguridad de gran parte de los países de la subregión.

En resumen, el análisis de la evolución temporal del valor del IFC permite concluir -con la debida cautela por el problema de atribución- que es probable que el incremento en términos reales de los compromisos de ApC canalizados hacia los países latinoamericanos desde el período base 2002-2005 hasta el período 2006-2010 haya contribuido positivamente al aumento del valor del IFC detectado en la práctica totalidad de los países de la muestra y en las tres subregiones consideradas. Desde esta perspectiva, la ApC habría favorecido la obtención de resultados en términos de mejora de la capacidad comercial de la mayor parte de los países receptores. Asimismo, del examen de los cuatro subíndices y de los nueve pilares que conforman el IFC, se aprecia que en las tres subregiones existe un potencial efecto positivo de la $\mathrm{ApC}$ en la mejora de la eficiencia de la administración aduanera (pilar 2) y de la infraestructura de transporte y comunicaciones (pilares 5, 6 y 7 ). 


\section{ENFOQUE CUALITATIVO: LOS RELATOS DE EXPERIENCIAS CONCRETAS}

En el último trimestre del año 2010, la OMC y la OCDE impulsaron una iniciativa para analizar los resultados de la ApC, consistente en invitar a los actores implicados en los proyectos y programas de ApC a presentar relatos de sus experiencias. Estos relatos se difundieron en 2011 por medio de su publicación en la página web de la OCDE. En el caso de la región de América Latina y el Caribe se presentaron 67 relatos, que constituyeron una cuarta parte del total de 269 relatos recopilados. ${ }^{12}$ A través de estos relatos, se pueden identificar las principales lecciones aprendidas en las experiencias presentadas y por ello, se incorporaron a la investigación.

En términos generales, los relatos de la región de América Latina y el Caribe coinciden en señalar tres factores básicos para el éxito de los proyectos y programas de ApC (OMC/BID/OCDE, 2011, p. 25). En primer lugar, la identificación del país beneficiario con el proyecto y el compromiso del donante son fundamentales para una intervención satisfactoria y sostenible en el tiempo. En segundo lugar, la participación del sector privado es esencial tanto en el establecimiento de las prioridades comerciales nacionales como en la ejecución de los proyectos de ApC. En este sentido, América Latina sigue el patrón mostrado por OECD/WTO (2009) que apunta a que la participación del sector privado se incrementa a medida que aumenta el grupo de renta al que pertenece el país analizado; esto es, es más frecuente en los países de renta media que en los países de renta baja. Por último, el tercer factor de éxito hace referencia a la presencia de mecanismos efectivos de coordinación nacional en los proyectos de $\mathrm{ApC}$, especialmente si en éstos intervienen más de un ministerio o hay un componente regional.

Con objeto de profundizar en la identificación de las lecciones aprendidas, se analiza a continuación la información recabada en cuatro relatos que constituyen ejemplos representativos de los proyectos de ApC en América Latina. Los cuatro relatos seleccionados son: Alianza público-privada y biodiversidad: la cadena de la maca en Perú (número de referencia del relato: 136); Cooperación triangular: el fortalecimiento de la gestión comercial e institucional de EXPORTA El Salvador (número de referencia del relato: 124); Integración regional: el Proyecto Mesoamérica (número de referencia del relato: 120); y Pequeñas y medianas empresas y acceso a los mercados de exportación: FINPYME Export Plus (número de referencia del relato: 121).

\footnotetext{
${ }^{12}$ Todos los relatos de experiencias concretas de ApC para América Latina pueden consultarse en la página web de la OCDE, en la siguiente dirección: http://www.oecd.org/document/36/ 0,3746,en_21571361_46750445_48184932_1_1_1_1,00.html.
} 


\section{Relato $n^{\circ}$ 1. Alianza público-privada y biodiversidad: la cadena de la maca en Perú}

El primer relato se engloba dentro del programa Perú Biodiverso, financiado por la cooperación de Suiza y Alemania. Este Programa tiene como contraparte al Ministerio de Comercio Exterior y Turismo de Perú, que lo ha impulsado dentro del Programa Nacional de Promoción del Biocomercio aprobado en 2002. Se ha pretendido promover cadenas de valor de productos y servicios relacionados con la biodiversidad del país, estableciendo una alianza productiva público-privada que favoreciera la reducción de la pobreza rural. La maca ${ }^{13}$ ha sido uno de los productos naturales seleccionados para impulsar una cadena de valor y de productos funcionales destinados a la industria alimenticia (en este caso, como producto nutricional). Las líneas centrales de actuación han sido la identificación de mercados, el desarrollo de una oferta de servicios y el fortalecimiento del marco institucional y legal del biocomercio.

Gracias a esta iniciativa se ha logrado el aumento del precio de la maca, lo que ha contribuido a incrementar el beneficio -tradicionalmente reducido- que recibían los productores rurales por su actividad económica. Asimismo, se ha mejorado la capacitación de los beneficiarios en la negociación con empresas privadas y se ha ampliado el conjunto de herramientas disponibles para los productores y transformadores de maca participantes en el proyecto. ${ }^{14}$

Este relato muestra que mediante un proyecto de $\mathrm{ApC}$ se puede hacer un buen uso comercial de la biodiversidad de un PED. El éxito del proyecto se ha sustentado especialmente en una eficiente articulación productiva entre el sector público y el privado, que ha logrado mejorar las condiciones de vida de las poblaciones rurales implicadas y la igualdad de género en dichas poblaciones (ya que se ha impulsado la participación de mujeres microempresarias). Otros dos factores importantes del éxito han sido el fortalecimiento de las capacidades técnicas y de gestión de las asociaciones de productores rurales para mejorar su participación en la cadena de valor de la maca, así como la adopción de incentivos para impulsar unos mayores estándares de calidad en dicha cadena (certificaciones orgánicas, semillas certificadas, normas técnicas, etc.). Con todo ello se ha logrado consolidar la maca en el mercado, desarrollar su oferta exportable más allá de los mercados locales y regionales y formar un equipo humano preparado para la gestión comercial.

${ }^{13}$ La maca es una planta originaria del Perú que presenta numerosas propiedades entre las que destacan, su valor como suplemento nutricional que le convierten en un producto muy demandado en los países desarrollados.

14 La asociación participante en esta iniciativa ha sido la Asociación de Productores y Transformadores de Maca Región Junín "Nación Pumpush". Entre las nuevas herramientas con las que cuenta dicha Asociación, se destacan el registro único de contribuyente, el establecimiento de una cuenta bancaria y la certificación orgánica de la producción. 


\section{Relato $n^{\circ}$ 2. Cooperación triangular: el fortalecimiento de la gestión comercial e institucional de EXPORTA El Salvador}

El segundo relato seleccionado se enmarca dentro del Programa de Asociación para la Cooperación Chile-Japón dirigido a impulsar la cooperación técnica entre los dos países. El relato presenta los resultados de una iniciativa de cooperación triangular en la que participaron esos dos países junto a El Salvador. El origen de la iniciativa se sitúa en 2004, cuando El Salvador estableció la promoción de exportaciones como una de sus estrategias prioritarias y para ello, creó una agencia específica denominada EXPORTA. La necesidad de buscar apoyos internacionales para ampliar su oferta exportable unida al conocimiento del modelo exitoso aplicado por la Dirección de Promoción de Exportaciones de Chile (ProChile), llevaron al gobierno salvadoreño a presentar ese mismo año una solicitud de cooperación técnica triangular al gobierno chileno, a través de la Agencia de Cooperación Internacional de Chile y con el apoyo financiero de Japón. ${ }^{15}$

El objetivo fundamental del proyecto fue el desarrollo de una oferta exportable para El Salvador, orientada a demandas específicas mediante el establecimiento de un sistema integrado de información comercial e inteligencia de mercado. El diseño y ejecución del proyecto se materializó en el desarrollo de capacidades a través de la realización de prácticas profesionales y asistencias técnicas, con las que se formaron los profesionales de la agencia EXPORTA.

La evaluación realizada en 2009 mostró que los resultados del proyecto en relación con las metas fijadas habían sido satisfactorios. Se había logrado fortalecer la capacidad de promoción de las exportaciones de un PED -El Salvadorgracias a la transferencia de buenas prácticas en este ámbito de otro PED -Chile- con la financiación de un donante del CAD -Japón-. Esta asistencia técnica Sur-Sur puso de manifiesto que en muchas ocasiones, las experiencias exitosas de otros PED -en lugar de las de los países donantes- resultan ser mucho más adecuadas para fortalecer la capacidad comercial. ${ }^{16}$

\section{Relato $n^{\circ}$ 3. Integración regional: el Proyecto Mesoamérica}

$\mathrm{El}$ tercer relato resalta la importancia de la dimensión regional de la $\mathrm{ApC}$, esto es, de los proyectos de ApC que benefician a más de un país dentro de la misma región. El Proyecto Mesoamérica -creado en 2008 para dar continuidad

${ }^{15}$ La primera Misión de Formulación del Proyecto se realizó en abril de 2005 y en noviembre del mismo año se firmó el convenio oficial. La duración del proyecto fue de tres años, desde agosto de 2006 a agosto de 2009.

${ }^{16}$ Sobre las posibilidades de la cooperación Sur-Sur, véase la página web: http://www.southsouth. info 
al Plan Puebla Panamá- ${ }^{17}$ se establece como un mecanismo de coordinación apoyado por el BID para articular los esfuerzos de integración de diez países: Belice, Colombia, Costa Rica, El Salvador, Guatemala, Honduras, México, Nicaragua, Panamá y República Dominicana. El BID actúa de catalizador de los recursos financieros y de los conocimientos técnicos requeridos.

El Proyecto Mesoamérica constituye un buen ejemplo de un proyecto regional en el que se contemplan -junto a otras áreas- cuatro áreas específicas de aplicación de la Iniciativa de la $\mathrm{ApC}$, en concreto: la facilitación del comercio, el transporte, la energía y las telecomunicaciones. ${ }^{18}$ Las áreas de infraestructura regional del Proyecto se conciben como un complemento esencial de las medidas de liberalización comercial para impulsar conjuntamente la integración regional y a partir de ella, el crecimiento económico. Para que este impulso conjunto de la integración mesoamericana sea efectivo, se ha percibido que es necesario contar con dos tipos de compromisos: en primer lugar, el compromiso político al más alto nivel (que es esencial para poder avanzar en los proyectos de integración regional); y en segundo lugar, el compromiso a largo plazo de un banco multilateral de desarrollo como el BID (que es fundamental para la provisión de apoyo técnico y financiero, lo que contribuye a superar las debilidades institucionales que podrían limitar la acción colectiva regional).

\section{Relato $n^{\circ}$ 4. Pequeñas y medianas empresas y acceso a los mercados de exportación: FINPYME ExportPlus}

El cuarto relato muestra los resultados de una iniciativa de la Corporación Interamericana de Inversiones (CII) iniciada en 2009 con el apoyo del Gobierno de Italia, cuyo objetivo fundamental es mejorar la capacidad de las pequeñas y medianas empresas (PYMES) para acceder a los mercados de exportación. En línea con la Iniciativa de ApC, el programa FINPYME ExportPlus se incluye dentro de la categoría de creación de capacidad productiva. ${ }^{19}$ Dado que la CII dispone de recursos financieros y humanos limitados, el programa incorpora como socios a una red de instituciones locales públicas y privadas implicadas en el comercio internacional.

El programa eligió a Guatemala como proyecto piloto y se centró en tres pilares básicos para mejorar la capacidad exportadora de las PYMES de este país. El primer pilar se configuró en torno a los procesos de certificación, en especial

\footnotetext{
${ }^{17}$ El Plan Puebla Panamá se creó en 2001 con el objetivo de impulsar la integración regional y el desarrollo de la región mesoamericana. Para más información sobre el Proyecto Mesoamérica, véase su página web en la siguiente dirección: http://www.proyectomesoamerica.org.

${ }^{18}$ Las otras áreas prioritarias del Proyecto Mesoamérica que no se vinculan a la Iniciativa de la $\mathrm{ApC}$, son: desastres naturales, salud pública, sostenibilidad medioambiental y vivienda.

${ }^{19}$ Para más detalles sobre este programa, véase su página web: http://www.finpyme.org.
} 
las certificaciones relacionadas con los estándares de calidad y los productos agrícolas. ${ }^{20} \mathrm{El}$ segundo pilar se construyó a partir de los procesos operativos, en concreto a partir de mejoras en el aparato productivo interno de las PYMES. El tercer y último pilar se basó en los procesos de gestión relacionados con la creación de capacidades en áreas como la gestión de exportaciones, el análisis de mercados, la gestión de proyectos y la planificación estratégica y logística.

La evaluación del programa piloto en Guatemala fue muy positiva, lo que llevó a ampliarlo a otros países centroamericanos y caribeños. La respuesta de las PYMES participantes a una encuesta de satisfacción mostró una puntuación media de 4,56 en una escala de 1-5, siendo 5 la máxima satisfacción. Otras respuestas destacadas en esa encuesta fueron que la mayor parte de las PYMES habían puesto en práctica acciones recomendadas durante el proceso de formación, alrededor de la mitad reconocieron percibir un incremento en su capacidad de exportación y más del 80\% de las PYMES mostraron su interés en invertir en actividades similares de formación en el futuro.

Este relato pone énfasis en la importancia de fortalecer las PYMES en el proceso de creación de capacidad comercial en un PED. Como un factor fundamental para el éxito del programa, se ha resaltado la presencia de socios fiables -como la CII y la red de apoyo de instituciones locales públicas y privadasque han actuado como puentes entre donantes y beneficiarios.

\section{CONCLUSIONES}

La Iniciativa de la ApC se lanzó en 2005 con el objetivo de articular una estrategia coherente de apoyo a los PED en su empeño de convertir el comercio en un instrumento de crecimiento económico y de este modo, de reducción de la pobreza. Los flujos de ApC destinados a los PED latinoamericanos no han estado entre los más privilegiados; de hecho, han representado tan sólo un 7\% del total mundial. El relativamente mayor nivel de renta per cápita de América Latina ha hecho que ésta ocupe una posición marginal en el total mundial. Sin embargo, ello no ha sido óbice para que la región no haya dejado de recibir flujos crecientes de ApC en términos reales.

En el contexto actual de ajustes presupuestarios por parte de numerosos donantes, el debate sobre el alcance de los resultados obtenidos con esos flujos se ha intensificado. El mantenimiento futuro de los flujos de ApC no va a estar

${ }^{20}$ Existe numerosos relatos de experiencias que inciden especialmente en las medidas sanitarias y fitosanitarias. En la mayor parte de los casos, se trata de proyectos de ApC destinados a la formación de los agricultores y funcionarios gubernamentales para lograr mayores niveles de inocuidad en los productos alimenticios y cumplir con las normas sanitarias y fitosanitarias internacionales. Dado el gran potencial exportador de América Latina en productos agrícolas, no es extraño el interés por presentar este tipo de relatos de experiencias de ApC. Para más información, véase OMC/BID/OCDE (2011). 
condicionado sólo por la disponibilidad de recursos, sino también -y de modo creciente- por la visibilización de resultados significativos en los proyectos y programas financiados en América Latina. La medición y evaluación de esos resultados no es una tarea sencilla. La limitada disposición de datos, así como los problemas de la atribución y del desfase temporal restringen por el momento, la capacidad de elaborar indicadores de resultados relevantes y comparables, y con ello, la aplicación de técnicas econométricas basadas en dichos indicadores.

Como un primer paso para responder a la necesidad de evaluar los resultados de la ApC en América Latina a partir de la información disponible, esta investigación optó por acometer una primera valoración de esos resultados mediante un doble enfoque metodológico. El primero -de carácter cuantitativo- se basó en el análisis del IFC preparado por el Foro Económico Mundial y el segundo -de carácter cualitativo- se fundamentó en el examen de los relatos de experiencias concretas de ApC en América Latina.

El análisis cuantitativo reveló un aumento del valor del IFC en la práctica totalidad de los 17 países latinoamericanos de la investigación y en las tres subregiones consideradas, lo que constituye un indicio de la potencial contribución positiva de la $\mathrm{ApC}$ en la obtención de resultados en los países receptores, especialmente en términos de mejora de sus capacidades comerciales. Asimismo, se detectaron dos áreas en las que los países latinoamericanos tienen margen para solicitar un aumento de los flujos de ApC e incrementar el potencial impacto positivo de los mismos: en concreto, la modernización de la infraestructura relacionada con el comercio y el fortalecimiento de la administración aduanera.

Por lo que respecta al análisis cualitativo de los relatos de experiencias de $\mathrm{ApC}$, se delimitaron siete lecciones aprendidas de esas experiencias, que pueden ayudar a mejorar los resultados de los proyectos y programas de ApC en América Latina. Esas lecciones son las siguientes: primera, la identificación del país receptor con el proyecto es esencial para la adecuada ejecución del mismo; segunda, la participación del sector privado -especialmente, en PED de renta media como los latinoamericanos- así como su eficiente articulación productiva con el sector público es un factor clave para el éxito de los proyectos; tercera, la efectiva coordinación nacional de los actores implicados -en particular, cuando hay varios ministerios participantes o el proyecto tiene un componente regional- es fundamental; cuarta, en la medida de lo posible, el desarrollo sostenible y la igualdad de género deberían ser componentes transversales de todos los proyectos de ApC; quinta, la cooperación Sur-Sur y triangular puede ser una buena vía para mejorar la eficacia de la $\mathrm{ApC}$; sexta, la dimensión regional de la $\mathrm{ApC}$ es relevante en una región como América Latina con varios procesos de integración subregional en funcionamiento; y séptima, el apoyo de la $\mathrm{ApC}$ a las 
PYMES en su acceso a los mercados internacionales puede contribuir a la creación de capacidad comercial.

\section{REFERENCIAS BIBLIOGRÁFICAS}

BASNETT, Y.; ENGEL, J.; KENNAN, J.; KINGOMBE, C.; MASSA, I. y WILLEM TE VELDE, D. (2012). Increasing the Effectiveness of Aid for Trade: The Circumstances under which It Works Best. Londres: Overseas Development Institute, Working Paper n. ${ }^{\circ} 353$.

BID (Banco Interamericano de Desarrollo) (2006). Ayuda para el comercio: la experiencia del Banco Interamericano de Desarrollo. Washington, DC: BID.

BID (2007). Movilizando la Ayuda para el Comercio en América Latina y el Caribe. Washington, DC: BID.

CADOT, O.; FERNANDES, A.M.; GOURDON, J. y MATTOO, A. (2011). Where to Spend the Next Million? Applying Impact Evaluation to Trade Assistance. Washington, DC: The World Bank.

DE LOMBAERDE, P. y LAKSHMI, P. (eds.) (2009). Aid for Trade: Global and Regional Perspectives. 2nd World Report on Regional Integration. Nueva York: Springer, United Nations University Series on Regionalism, vol. 2.

ECLAC (United Nations Economic Commission for Latin America and the Caribbean) (2009). "Aid for Trade: Strengthening Latin American and Caribbean International Linkages and Regional Cooperation". En De Lombaerde, P. y Lakshmi, P. (eds.): Aid for Trade: Global and Regional Perspectives. 2nd World Report on Regional Integration. United Nations University Series on Regionalism, Vol. 2. Nueva York: Springer.

GARCÍA-LÓPEZ, R. y GARCÍA-MORENO, M. (2010). La gestión para resultados en el desarrollo: avances y desafíos en América Latina y el Caribe. Washington, DC: BID.

HOEKMAN, B. y PROWSE, S. (2005). Economic Policy Responses to Preference Erosion: From Trade as Aid to Aid for Trade. World Bank Policy Research Working Paper $\mathrm{n}^{\circ}$. 3721. Washington, DC: The World Bank.

HOEKMAN, B. y WILSON, J.S. (2010). Aid for Trade: Building on Progress Today for Tomorrow's Future. World Bank Policy Research Working Paper $n^{\circ}$. 5361. Washington, DC: The World Bank.

IMF/WORLD BANK (International Monetary Fund/World Bank) (2005). Doha Development Agenda and Aid for Trade. DC2005-0016. Washington, DC: IMF y World Bank.

LAWRENCE, R. Z.; HANOUZ, M. D.; GEIGER, T. y HE, Q. (2009). "Enabling Trade in the Global Crisis". En WEF (World Economic Forum): The Global Enabling Trade Report 2009. Ginebra: WEF. 
MUDARRA, F. (2012). "La Gestión para Resultados de Desarrollo (GpRD) en los proyectos de cooperación internacional". En Salazar, M.E. y Pablo, C.M. (eds.): La eficacia de la ayuda para el agua y el saneamiento. Un análisis de la cooperación descentralizada. Madrid: Secretariado de Alianza por el Agua/ECODES.

NJINKEU, D. y CAMERON, H. (eds.) (2008). Aid for Trade and Development. Nueva York: Cambridge University Press.

OCDE (Organización para la Cooperación y el Desarrollo Económico) y Banco Mundial (2006). Buenas prácticas recientemente identificadas de gestión para resultados de desarrollo. París: OCDE

OCDE y BANCO MUNDIAL (2007). Buenas prácticas emergentes de la Gestión para Resultados de Desarrollo. Libro de consulta. Segunda edición. París: OCDE.

OCDE y BANCO MUNDIAL (2008). Buenas prácticas emergentes en la Gestión para Resultados en el Desarrollo. Libro de consulta. Tercera edición. París: OCDE.

OECD (Organisation for Economic Co-operation and Development) (a). International Development Statistics on line Databases on Aid and Other Resource Flows. Disponible en: http://www.oecd.org/dataoecd/50/17/ 5037721.htm. [Último acceso: Octubre de 2012].

OECD (2006). Aid for Trade: Support for an Expanding Agenda. COM/DCD/TD2006-2, 8 de marzo. París: OECD.

OECD (2008). Reporting on Aid for Trade to the Creditor Reporting System. COM/DCD/TAD-2008-10, 8 de septiembre. París: OECD.

OECD (2009a). "Trading Out of Poverty. How Aid for Trade Can Help?". OECD Journal of Development, 10 (1).

OECD (2009b). Binding Constraints to Trade Expansion: Aid for Trade Objectives and Diagnostic Tools. OECD Trade Policy Working Paper $n^{\circ}$. 94. París: OECD.

OECD (2011a). Busan Partnership for Effective Development Co-operation. París: OECD.

OECD (2011b). Strengthening Accountability in Aid for Trade. The Development Dimension. París: OECD.

OECD/WTO (Organisation for Economic Co-operation and Development I World Trade Organization) (2007). Aid for Trade at a Glance 2007: $1^{\text {st }}$ Global Review. París y Ginebra: OECD/WTO.

OECD/WTO (2009). Aid for Trade at a Glance 2009: Maintaining Momentum. París y Ginebra: OECD/WTO.

OECD/WTO (2011). Aid for Trade at a Glance 2011: Showing Results. París y Ginebra: OECD/WTO.

OMC (Organización Mundial del Comercio) (2006). Recomendaciones del Equipo de Trabajo sobre la Ayuda para el Comercio. WT/AFT/1, 27 de julio. 
Ginebra: OMC.

OMC/BID (Organización Mundial del Comercio / Banco Interamericano de Desarrollo) (2009). Implementación de la Ayuda para el Comercio en América Latina y el Caribe: reuniones de revisión nacionales y regionales 20082009. Ginebra/Washington, DC: OMC/BID.

OMC/BID/OCDE (Organización Mundial del Comercio / Banco Interamericano de Desarrollo / Organización para la Cooperación y el Desarrollo Económico) (2011). Relatos de experiencias concretas en América Latina y el Caribe: Visión general de la ayuda para el comercio sobre el terreno". Ginebra/Washington, D.C./París: OMC/BID/OCDE.

PAGE, S. (2007). The Potential Impact of the Aid for Trade Initiative. G-24 Discussion Paper Series $n^{\circ}$. 45. Ginebra: UNCTAD.

PNUD (Programa de las Naciones Unidas para el Desarrollo) (2009). Manual de planificación, seguimiento y evaluación de los resultados de desarrollo. Nueva York: PNUD.

RUEDA-JUNQUERA, F. y GOZALO-DELGADO, M. (2011). Eficacia de la ayuda para el comercio en América Latina: implicaciones de la Declaración de París. Madrid: Fundación Carolina, Avances de Investigación n. ${ }^{\circ} 57$.

UNDP (United Nations Development Programme) (2008). Aid for Trade and Human Development. Nueva York: UNPD.

WEF (World Economic Forum) (2009). The Global Enabling Trade Report 2009. Ginebra: WEF.

WEF (2010). The Global Enabling Trade Report 2010. Ginebra: WEF.

WEF (2012). The Global Enabling Trade Report 2012. Ginebra: WEF. 
